\title{
https://doi.org/10.30853/manuscript.2019.11.55
}

\section{Цзи Шаньшань}

\section{МУЗЫКАЛЬНЫЙ МАТЕРИАЛ В КИТАЙСКИХ УЧЕБНИКАХ СОЛЬФЕДЖИО}

В статье рассматривается музыкальный материал, используемый в рамках вузовского предмета "сольфеджио" в современном Китае. В китайской практике развития музыкального слуха усвоена установка на разнообразие ритмов, ладов и мелодий различных национальных музыкальных языков, используемая в российском опыте воспитания музыканта. В предложенной работе автор дает краткий анализ учебных пособий Ли Чунгонга "Теория музыки", Сюй Цзина и Сунь Хуна "Сольфеджио", Ян Тонга "Учебник по гармоническому анализу", Лю Чжипина "Передовые методы обучения вокалу".

Адрес статьи: www.gramota.net/materials/9/2019/11/55.html

\section{Источник}

\section{Манускрипт}

Тамбов: Грамота, 2019. Том 12. Выпуск 11. С. 292-295. ISSN 2618-9690.

Адрес журнала: www.gramota.net/editions/9.html

Содержание данного номера журнала: www.gramota.net/materials/9/2019/11/

\section{() Издательство "Грамота"}

Информация о возможности публикации статей в журнале размещена на Интернет сайте издательства: www.gramota.net Вопросы, связанные с публикациями научных материалов, редакция просит направлять на адрес: hist@gramota.net 


\title{
SPECIFICITY OF MUSICAL STYLISTICS OF THE SICHUAN OPERA
}

\author{
Xu Jian \\ Herzen State Pedagogical University of Russia, Saint Petersburg \\ 251104247@qq.com
}

The article examines a unique form of the traditional Chinese drama - opera of the Sichuan province, or the Sichuan opera. It differs cardinally from the world-famous Peking opera and other local forms of opera art. The Sichuan opera has its own aesthetics, technique and school of singing, but its basic heritage is a unique musical style, which combines original singing in high register (gaoqiang) to the accompaniment of percussion instruments (luogu jing) with vocal and choral recital (banqiang). The author analyses the features of the vocal stylistics of the Sichuan opera, describes percussion instruments in detail and presents types of choral commenting used in the opera.

Key words and phrases: traditional Chinese drama; regional specificity; Sichuan opera; high tunes gaoqiang; vocal and choral recital; accompaniment of percussion instruments (luogu jing).

УДК 78; 781

https://doi.org/10.30853/manuscript.2019.11.55

Дата поступления рукописи: 02.09.2019

В статье рассматривается музыкальный материал, используемый в рамках вузовского предмета «сольфеджио» в современном Китае. В китайской практике развития музыкального слуха усвоена установка на разнообразие ритмов, ладов и мелодий различных начиональных музыкальных языков, используемая в российском опьте воспитания музыканта. В предложенной работе автор дает краткий анализ учебных пособий Ли Чунгонга «Теория музыки», Сюй Цзина и Сунь Хуна «Сольфеджио», Ян Тонга «Учебник по гармоническому анализу», Лю Чжипина «Передовые методы обучения вокалу».

Ключевые слова и фразы: воспитание слуха; учебные пособия; Лю Чжипин; Ян Тонг; музыкальный материал; интонирование; традиционная культура; западные методики.

\section{Цзи Шаньшань}

Российский государственный педагогический университет имени А. И. Гериена, г. Санкт-Петербург 48632593@qq.com

\section{МУЗЫКАЛЬНЫЙ МАТЕРИАЛ В КИТАЙСКИХ УЧЕБНИКАХ СОЛЬФЕДЖИО}

Актуальность работы заключается в том, что в настоящее время в Китае усилился интерес к вопросам воспитания музыкального слуха, однако исследований, в полной мере освещающих эту проблему, не существует. Одним из важнейших компонентов воспитания музыкального слуха является музыкальный материал, используемый в учебниках сольфеджио. Вестернизация музыкальной культуры, под знаменем которой в сложной исторической обстановке происходило становление музыкального образования, прочно проникла и в воспитание и развитие музыканта. Именно музыкальный материал сольфеджио показателен и интересен как фактор, отражающий преломление западных музыкально-языковых элементов и совмещение их с национальными в среде обучения музыкантов.

Объект исследования данной статьи - музыкальный материал в учебниках сольфеджио; предмет - статус и специфика этой дисциплины в Китае. Цель работы - раскрыть некоторые проблемы воспитания музыкального слуха и дать характеристику используемого музыкального материала. Существующая литература по данной проблеме немногочисленна. Можно выделить «Методические статьи по сольфеджио» Ван Гуаняо [2], «Историю развития шанхайской школы Сюй Хуэ. 1850-2010» Ма Сюэйцяна [6], «Изучение полного учебного курса сольфеджио в Ухане» Хуан Цяня [8], «Классифицированный курс сольфеджио. Уровни 1-8» коллектива авторов [5], тезисы «Цели и задачи сольфеджио в Китае» Чжао Ишаня [9], которые в некоторой степени восполняют этот пробел. Однако «вопросы развития музыкального слуха в Китае требуют глубокого изучения» [3, с. 36]. Научная новизна заключена в том, что впервые рассмотрены некоторые учебные пособия и музыкальный материал, способствующий активному развитию слуха.

В конце XX - начале XXI века отмечается усиление интереса к этническим культурам, в том числе к этническим ритмам, к этнической мелодике, к этносольфеджио. В России, например, в музыкальные пособия подобного рода включены звукоряды и ритмические формулы традиционной восточной музыки Турции, Ирана, Греции, Индии, Кореи, Китая и других стран. Благодаря ритмам, ладам и мелодиям различных национальных музыкальных языков студенты могут воспринять и познакомиться с элементами многих новых музыкальных культур. В китайском опыте развития музыкального слуха происходит то же самое. Известно, что «становление системы музыкального образования в Китае вначале происходило под влиянием зарубежных методик музыкального образования и, в частности, российской музыкальной школы, но в то же время формировалась собственная уникальная система» [14, с. 309]. 
Ученые уже давно установили связь между тоновой системой разговорного языка и развитием музыкального слуха: маленькие дети, которые рано начали изучать китайский язык, обладают очень хорошим музыкальным слухом. Система китайского языка содержит тональный фактор, и в зависимости от того, каким тоном произносятся слоги и слова, смысл меняется. Китайские дети очень рано начинают точно интонировать и различать ладовые нюансы в музыке. Для того чтобы всесторонне развивать слух, китайские музыканты, педагоги, методисты, наряду с использованием зарубежного музыкального материала, с конца ХХ столетия «активно формируют национальный интонационный материал и создают свои учебные пособия» [15, с. 234]. Некоторые преподаватели сольфеджио создают авторскую методику, которая четко нацелена на формирование певческих умений у студентов. В работе с пианистами они делают акцент на развитие гармонического слуха, с вокалистами и струнниками - мелодического, с ударниками и духовиками - огромное внимание уделяется ритму.

В настоящий период времени сложились благоприятные условия для развития музыкального слуха, что дает возможность совершенствовать подходы к формированию слуховых и певческих умений. Взятые за основу китайскими музыкантами современные европейские программы по сольфеджио доказали, что важно широко использовать национальные традиции, что повысит эффективность работы. Народная музыка, сопровождая ребенка с самого рождения, наиболее близка ему и понятна. Привлечение народных песен «позволит эффективно решать вопросы развития музыкального слуха в Китае» [7, с. 48]. Важно в пении со словами обращать внимание на артикуляцию и правильное дыхание, которое составляет особый комплекс техник в народной культуре. Однако именно пение по нотам часто отстает у учеников среди других умений. Точное воспроизведение нотного текста достигается тщательной проработкой текста. Чистое и точное интонирование - вот цель, к которой должен стремиться каждый педагог-сольфеджист.

Известно, что весьма полезной является работа над интервалами и аккордами. Педагог должен выбирать те мелодические интервалы, которые будут встречаться в разучиваемом материале. Интервальные последовательности постепенно следует усложнять, использовать цепочки интервалов в виде различного рода секвенций, прорабатывать каждый интервал от разных звуков лада. Китайские сольфеджисты стали активно включать в работу интервалы в двухголосии в виде совместного пения или пения одного голоса с одновременной игрой другого. Студентам-духовикам предлагается пропеть интервальную последовательность, вокалистам досочинить к двухголосному фрагменту окончание или пропущенные такты, пианистам - сочинить аккомпанемент. Содержание упражнений, как отмечают педагоги, «будет зависеть от методических целей занятий и каждый раз может свободно варьироваться» [13, с. 152].

Китайские педагоги в настоящее время уделяют повышенное внимание пению с листа. Они считают, что чрезвычайно важно начинать эту работу как можно раньше. Как отмечает петербургский исследователь Г. В. Абдуллина, учащиеся приобретут уверенность и научатся «охватывать слухом произведение в целом, что станет основой для подлинно артистичного исполнения... без чего немыслима будущая творческая деятельность музыканта» [1, с. 3].

Одним из ярких свидетельств процесса формирования собственной системы воспитания слуха является учебное пособие «Теория музыки» Ли Чунгонга. Оно состоит из пятнадцати глав, посвященных звуку, нотному письму, ритму и метру, интервалам, ладам и тональностям, аккордам, темпам в музыке, орнаментике. В конце каждого раздела приводятся контрольные вопросы и задания для проверки знаний. Пособие представляет собой адаптацию российских «классических» учебников по элементарной теории музыки (И. Способина, В. Вахромеева и др.). Привлекает внимание то, что некоторые нотные примеры приведены из музыки китайских композиторов, а приложение представляет собой объяснение упрощенной нотной записи (цифровой), распространенной в Китае для массового исполнения. Это очень важный момент, т.к. запись музыкальных фрагментов будет понятна и ученикам, не владеющим европейской нотной записью. Отдельная глава отводится пентатонике, пять основных тонов которой, наряду с 12-ступенной хроматической системой, составляют основу традиционной китайской музыкальной теории. Пособие «предназначено для учащихся профильных музыкальных заведений, но может использоваться и для работы по воспитанию слуха с учащимися других учебных заведений» [10, с. 133].

Учебное пособие «Сольфеджио» Сюй Цзина и Сунь Хуна предназначено, как указывают авторы, для «преподавателей, студентов колледжей, а также для преподавателей начальной и средней школы» [12, с. 8]. Оно состоит из трех глав и 22 тем (уроков). Каждый урок разделен на несколько частей для объяснения и обучения: объяснение теоретического материала, упражнения и одноголосные примеры для интонирования, ритмические упражнения, прослушивание (слуховой анализ). В конце каждой темы дается домашнее задание. Учебное пособие построено по принципу постепенного усложнения теоретического материала и практических упражнений. В нем охвачены все элементы музыкальной речи - строение клавиатуры фортепиано (разделение на октавы), звукоряд, интервалы, аккорды и их обращения, темп, метр, ритм, лад и тональность. Изучаются только скрипичный (соль) и басовый (фа) ключи, нет темы, посвященной ладам народной музыки. В конце учебного пособия содержится небольшой список музыкальных терминов и обозначений. В отличие от российских учебно-методических пособий, достаточно много практических заданий представляют собой схематически упрощенные записи, используемые в Китае в массовом музыкальном обиходе.

«Учебник по гармоническому анализу» Ян Тонга [16] состоит из двух больших частей: теоретической части и нотной хрестоматии для гармонического анализа. В теоретическом разделе рассматриваются: роль гармонии в музыке, все разновидности аккордов, значение метра и ритма в гармонии. В конце каждого раздела находятся контрольные вопросы для проверки знаний. Нотные примеры в хрестоматии приводятся 
из западноевропейской музыки (Ф. Куперен, Д. Скарлатти, И. С. Бах, К. Глюк, Й. Гайдн, Л. Бетховен, Ф. Шуберт, И. Брамс, Э. Григ, Р. Леонкавалло, Х. Вольф и др.), русской музыки (П. Чайковский, С. Прокофьев, М. Мусоргский), из произведений китайских композиторов (Хуан Цзы, Сянь Синхай, Лю Сюэн, Ван Синь, Цюй Си Сиань и др.). Произведения китайских авторов представлены в основном песнями гимнического склада на патриотическую тематику («Пение Родины», «Великая стена», «Сохраните военную песню», «Люди во всем мире»). Их особенностью является сочетание европейской и китайской традиционной интонационности. Подспорьем в учебной работе являются словари музыкальных иностранных терминов, содержащие термины, определения и понятия на итальянском, немецком, французском, английском языках с переводом на китайский язык. Сейчас в Китае на занятиях по сольфеджио очень востребованы труды Чэнь Цжунцзы «Методика преподавания музыки» (1926), «Преподавание музыки в начальных учебных заведениях» (1933). Базой для написания «Методики» послужили лекции профессора Кусакавы Норио в Токийской школе музыки, которую закончил Чэнь Цжунцзы. Ссылки в работе даются в основном на ноты самых популярных китайских и западных произведений тех лет. Десять глав книги включают в себя упражнения для развития дыхательного аппарата, голоса, слуха; знакомят читателя с терминологией и понятиями - лада, гаммы, интервала, метра; дают рекомендации по методике преподавания. Несмотря на то, что сольфеджио вовсе не становится краеугольным камнем, «Методика» включала в себя чрезвычайно много передовых идей. Можно смело утверждать, что для своего времени она стала новаторской.

Труд Лю Чжипина «Передовые методы обучения вокалу», где автор обобщил свой многолетний педагогический опыт, был издан в 1932 году. Пособие четко структурировано и «предназначено для студентов консерваторий и других профильных учебных заведений» [11, с. 2]. По материалам, включенным в сборник (песни, пьесы и народные инструментальные мелодии), можно определенно судить об уровне преподавания того времени. Данное сочинение помогает лучше понять историю воспитания музыкального слуха в стране на примере того, как педагог отбирает практический материал. Автор считает главным лишь мелодию, текст песен не играет роли. Введение понятия «гармония» стало новаторским веянием, позволило сделать музыкальный материал учебника более доступным и законченным. Это учебное пособие выделялось на фоне остальных в те годы, став вскоре одним из самых востребованных.

В 2009 году «Передовые методы обучения вокалу» вышли в новой редакции. Пособие значительно расширилось и дополнилось. Все его разделы также основаны на постепенном усложнении материала. В первом разделе «Освоение диатонических интервалов» представлены инструктивные упражнения в до мажоре. Все интервалы, простые размеры и длительности включаются постепенно. Затем идет освоение минорного лада и включаются уже простые фрагменты из сочинений композиторов. Раздел пентатоники представлен китайскими народными песнями.

В разделе, где осваиваются все мажорные и минорные тональности, значительно усложняются ритмические формулы, появляются триоли и синкопы, пунктирный ритмический рисунок и затакт. Несколько разделов учебника, в которых используются достаточно сложные фрагменты из симфонической и оперной музыки П. И. Чайковского, Н. А. Римского-Корсакова, А. И. Хачатуряна, Д. Верди, Д. Россини, В. А. Моцарта, Ф. Мендельсона и других композиторов, посвящены альтерации, отклонениям и модуляциям в родственные тональности. Постепенно осваиваются модуляции в далекие тональности. В сборнике имеются разделы, посвященные освоению секвенций, интонационным ходам на широкие интервалы, разнообразным синкопированным формулам и другим сложным ритмическим рисункам. Отдельный раздел посвящен джазовой, рок, блюз, кантри и современной американской музыке. Привлекают внимание музыкальные фрагменты из произведений П. Хиндемита, И. Стравинского, А. Шенберга, Б. Бартока, А. Веберна, О. Мессиана, содержащие сложные ритмические элементы и хроматические ходы, которые будут вполне доступны уже подготовленным студентам.

Во второй части учебного пособия представлены двухголосные примеры. Материал также построен по принципу постепенного усложнения. В начале предлагается инструктивный материал - простое гармоническое двухголосие, основанное на параллельных терциях и секстах. Затем автор предлагает каноны, взятые из российских и французских сборников по сольфеджио. В конце части представлены двухголосные фрагменты с аккомпанементом из композиторского творчества. В этом разделе в основном представлен материал из французских сборников по сольфеджио.

Третья часть - это трехголосные примеры из сборника двухголосного сольфеджио И. Способина и фрагменты из кантат И. С. Баха. В последнем разделе представлены достаточно сложные многоголосные фрагменты из сочинений Б. Сметаны, А. Дворжака, К. М. Вебера, американских композиторов и обработки русских народных песен. Музыкальный материал этой части достаточно сложный и доступен только подготовленным студентам. Фрагменты включают переменные размеры, сложные ритмические группы, трудно исполняемые интонационные скачки.

В конце сборника Лю Чжипин помещает краткие сведения о композиторах, чьи фрагменты были использованы, дает пояснение основным терминам и показывает дирижерские схемы. В предисловии он отмечает: «...в процессе написания данной работы мы использовали зарубежные и китайские музыкальные материалы по пению с целью свести воедино все известные методики. Так была сформирована комплексная система обучения с широким охватом, богатым содержанием и выбором материалов» [Там же].

В воспитании слуха огромное значение китайские педагоги придают и развитию слуха тембрового. Кроме тембра фортепиано, к которому учащиеся привыкают с раннего детства, занимаясь на инструменте, преподаватели сольфеджио на уроках используют тембры цифрового фортепиано, синтезатора, народных инструментов. 
В настоящее время это все достижимо благодаря мобильным приложениям, хорошему оснащению классов компьютерными программами и специальными устройствами. Российский исследователь М. Карасева отмечает, что «работа с музыкальными инструментами - и с акустическими, и с цифровыми - так или иначе способствует развитию тембрового слуха» [4, с. 165].

Таким образом, рассмотренный музыкальный материал и созданные китайскими теоретиками учебные пособия для работы по развитию музыкального слуха учеников позволяют говорить о том, что методика воспитания слуха, включающая грамотное интонирование, освоение интервалов и аккордов, ладов и тональностей, слуховой анализ и сольфеджирование национальной музыки и фрагментов из сочинений русских и европейских композиторов, продолжает быстро развиваться в настоящее время. Педагоги наряду с народной музыкой используют достижения мировой классики, что способствует не только выработке новых практических умений у китайских студентов, но и приобщает их к мировой музыкальной культуре.

Список источников

1. Абдуллина Г. В. Тренинг беглого интонирования: учебное пособие для старших классов ДМШ, музыкальных училищ и вузов. СПб.: Композитор, 2015. 100 с.

2. Ван Гуаняо. Методические статьи по сольфеджио. Сиань: Тайбай Вэньи, 1999. 117 с.

3. Ишань Чжао. Цели и задачи сольфеджио в Китае // Современное сольфеджио: тезисы Международной научнопрактической конференции (г. Москва, 8-10 ноября 2011 г.). М.: Московская гос. консерватория им. П. И. Чайковского, 2011. С. 35-40.

4. Карасева М. В. «Дополненная реальность» в работе педагога-музыканта // Научный вестник Московской консерватории. 2016. № 2 (25). С. 141-183.

5. Классифицированный курс сольфеджио. Уровни 1-8 / под общ. ред. Сюй Цзинсин. Пекин: Народное издательство, 2007. $313 \mathrm{c}$.

6. Ма Сюэйцян. История развития шанхайской школы Сюй Хуэ. 1850-2010. Шанхай: Издательство Шанхайской консерватории, 2010. $247 \mathrm{c.}$

7. Хао Чжоя. Профессиональный учебный курс сольфеджио в Китае // Современное сольфеджио: тезисы Международной научно-практической конференции (г. Москва, 8-10 ноября 2011 г.). М.: Московская гос. консерватория им. П. И. Чайковского, 2011. С. 45-56.

8. Хуан Цянь. Изучение полного учебного курса сольфеджио в Ухане // Теория и методика музыкальной композиции: сб. науч. тр. / под ред. Ма Исюань. Ухань: Чанцзян Вэньи, 2008. С. 37-46.

9. Чжао Ишань. Цели и задачи сольфеджио в Китае // Современное сольфеджио: тезисы Международной научнопрактической конференции (г. Москва, 8-10 ноября 2011 г.). М.: Моск. гос. консерватория им. П. И. Чайковского, 2011. C. 67-62.

10. 李中功 音樂理論. 北京：國家音樂出版社， 2012. 135 頁 (Ли Чунгонг. Теория музыки. Пекин, 2012. 135 с.).

11. 劉繼平 先進的聲音訓練方法. 綜合視唱練耳指南孔雲霞 上海, 1934. 340 頁 (Лю Чжипин. Передовые методы обучения вокалу: комплексное руководство по сольфеджио / гл. ред. Кон Юнься. Шанхай: Издательство Шанхайской консерватории, 1934. 340 с.).

12. 徐靜, 孫紅聽力訓練. 北京：國家音樂出版社, 2011. 168 頁 (Сюй Цзин, Сунь Хун. Сольфеджио. Пекин, 2011. 168 с.).

13. 夏延洲 收集中國現代音樂史. 上海，上海音樂出版社，2004. 154 頁 (Ся Яньчжоу. Сборник по истории современной китайской музыки. Шанхай: Шанхайская музыкальная пресса, 2004. 154 с.).

14. 娟子 現代教育理論. 北京，國民教育， 2005. 620 頁 (Хуан Зи. Теория современного образования. Пекин, 2005. 620 с.).

15. 蔡紀周 音樂理論與音樂學科理論. 上海, 上海音樂, 2007. 335 頁 (Цай Цзичжоу. Теория музыки и теория музыкальных дисциплин. Шанхай, 2007. 335 с.).

16. 楊肜諧波分析教程. 北京：國家音樂出版社， 2013 年. 170 頁 (Ян Тонг. Учебник по гармоническому анализу. Пекин, 2013. 170 с.).

\title{
MUSICAL MATERIAL IN THE CHINESE TEXTBOOKS ON SOLFEGGIO
}

\author{
Ji Shanshan \\ Herzen State Pedagogical University of Russia, Saint Petersburg \\ 48632593@qq.com
}

The article examines musical material used in teaching the higher school solfeggio course in modern China. The Chinese techniques of musical ear development are based on the approach established in the Russian system of musical education and focused on the diversity of national rhythms, scales and melodies. The author provides a concise analysis of textbooks "Theory of Music" by Li Zhonggong, "Solfeggio" by Xu Jing and Sun Hong, "Textbook on Harmonic Analysis" by Yang Tong, "Advanced Methods of Vocal Training" by Liu Jiping.

Key words and phrases: musical ear training; textbooks; Liu Jiping; Yang Tong; musical material; intoning; traditional culture; western methodologies. 